\title{
Uma abordagem analítica do problema da dispersão de contaminantes em rios e canais
}

\author{
Renata Oliveira Régis Quadros Fabrício Harter Guilherme Weymar \\ Programa de Pos-Graduação em Matemática Aplicada - PPGMMat, UFPel \\ Campus Capão do Leão, Pelotas, RS \\ E-mail: renata_engracio@hotmail.com,quadros99@gmail.com, fpharter@gmail.com,
} guicefetrs@gmail.com

\section{RESUMO}

Nos últimos tempos tem aumentado de maneira significativa à preocupação com relação a problemas ambientais gerados pelos processos industriais, geração de energia e tratamento de rejeitos. Em cidades onde se concentra um alto índice populacional e industrial, os problemas são ainda maiores devido a uma maior atividade humana gerando resíduos, denominados poluentes, que causam impactos indesejáveis ao meio ambiente.

Uma questão de suma importância é com relação à água, pois sua disponibilidade no planeta é limitada. A água doce está cada vez mais escassa e seu valor está cada vez mais alto devido ao aumento da necessidade de consumo para diversos usos, fazendo com que a escassez da mesma torne-se o principal foco das discussões sobre poluição ambiental. Atribuem-se como principais fatores que contribuem para a degradação dos corpos hídricos: a falta de saneamento básico, o lançamento de efluentes industriais não devidamente tratados, projetos de irrigação, o desmatamento e a exploração dos recursos hídricos para fins energéticos.

Com o avanço computacional, a modelagem matemática surgiu como uma alternativa para prever o comportamento dos escoamentos e dispersão de poluentes. Tais modelos matemáticos contribuem, por exemplo, em projetos de estações de tratamento de esgoto, na determinação da influência de obras hidráulicas na qualidade da água, vazamentos acidentais de resíduos tóxicos.

O objetivo do presente artigo está na solução de um modelo bidimensional em regime permanente de dispersão de poluentes em rios e canais. A solução deste problema será obtida analiticamente pela técnica GILTT (do inglês "Generalized Integral Laplace Transform Technique") [3]. Esta técnica está bem estabelecida e tem sido aplicada com grande sucesso para modelar a dispersão de poluentes na atmosfera. Aqui apresentaremos uma extensão do método resolvendo um problema de dispersão em rios. $O$ enfoque principal está no desenvolvimento de modelos mais gerais que incluem informações relevantes ao processo de dispersão de poluentes em rios e canais. O modelo que discutiremos foi formulado com base nos conceitos e processos físicos que governam o fenômeno e é válido para qualquer perfil de velocidade e difusividade turbulenta variável nas direções longitudinal e vertical. A GILTT é usada para prever o comportamento do poluente dispersado, sendo este um método espectral que combina uma expansão em série com uma integração.

Cabe salientarmos que soluções analíticas são fundamentais na modelagem uma vez que elas são econômicas e eficientes, tornando-se convenientes para uma análise mais ampla. Neste trabalho apresentaremos uma solução para um problema bidimensional no plano longitudinal e vertical em regime permanente que modela a dispersão de poluentes em rios e canais. Este tipo de modelo bidimensional de transporte é normalmente utilizado para rios ou canais cuja profundidade tem um papel relevante no processo de difusão e advecção de massa. A formulação do problema proposto, em forma adimensional, é descrito por:

$$
u \frac{\partial C}{\partial X}+w \frac{\partial C}{\partial Z}=\frac{\partial}{\partial Z}\left(\varepsilon_{Z} \frac{\partial C}{\partial Z}\right)-\lambda C
$$

onde $u$ é a velocidade de escoamento longitudinal e $w$ a velocidade vertical; $C$ é a concentração adimensional do poluente; $\varepsilon_{Z}$ a difusividade adimensional; $\lambda$ o coeficiente de reação química adimensional; $Z$ e $X$ as coordenadas espaciais adimensionais, definidas por $Z=\frac{z}{d} ; X=\frac{x}{d} \mathrm{e}$ 
$d$ a profundidade do rio. A equação (1) está sujeita as seguintes condições de contorno de fluxo nulo em $Z=0$ e $Z=1$ e em $X=0$ tem-se $C(0, Z)=\delta\left(Z-Z_{o}\right)$.

$\mathrm{Na}$ sequencia apresenta-se uma comparação do modelo proposto com 2 modelos bidimensionais de transporte de poluentes em rios e canais: $\mathrm{O}$ primeiro, desenvolvido por Barros [1], utiliza a técnica da transformada integral generalizada (GITT), uma técnica híbrida, analítico-numérica. Esta solução faz uso da hipótese de desprezar correntes secundárias de forma que o perfil de velocidade existente é descrito pela componente longitudinal que pode variar ao longo de x e de z. O coeficiente de difusão turbulenta também varia nas mesmas direções. Considera-se que não há perda de massa nas fronteiras (tanto do leito quanto na superfície livre do rio ou canal). O segundo modelo, desenvolvido por Nokes et al. [4] não incorpora variações longitudinais nem termos de decaimento químico. Nokes et al. [4], experimentalmente, simulou a dispersão de uma solução contendo $\mathrm{NaCl}$ em um canal de $15 \mathrm{~m}$ de comprimento e profundidade de $15 \mathrm{~cm}$. A largura do canal era de $560 \mathrm{~mm}$ e sua velocidade média é de $0,55 \mathrm{~m} / \mathrm{s}$. A constante de Von Karman, $\kappa$, é de 0,35 e a velocidade de atrito, ${ }_{\mathrm{f}}{ }_{\mathrm{f}}$, é de $0,055 \mathrm{~m} / \mathrm{s}$. Estes dados, $\kappa \mathrm{e} \mathrm{u}_{\mathrm{f}}{ }^{*}$, foram extraídos de medidas experimentais e foram utilizados por Nokes et al. [4]. A fonte poluidora é pontual e está centrada em $\mathrm{Z}_{\mathrm{o}}=0,75$.

Os perfis, já adimensionalisados adotados na simulação foram [4]:

$$
U(z)=1+\frac{u_{f}^{*}}{u_{a v} \kappa}[1+\ln (z)] \quad \epsilon_{z}(z)=\frac{u_{a v} \kappa}{u_{f}^{*}} z(1-z)
$$

O gráfico apresentado na figura 1 mostra a comparação entre os resultados analíticos obtidos via GILTT, o híbrido via GITT [1] e os experimentais [4]. Percebe-se que há uma boa concordância entre os resultados exceto por pequenas diferenças. Estas podem ser explicadas pelo fato de que [4] apresenta uma solução aproximada para o problema de dispersão vertical.

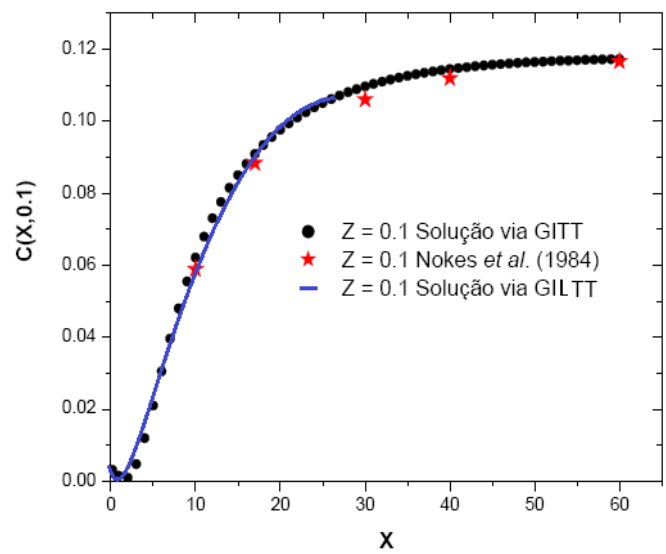

Figura 1: Validação do modelo analítico bidimensional em $\mathrm{Z}=0,1$ comparado com resultados da literatura, [1][4]

Palavras-chave: Método Espectral, Solução Analítica, Dispersão de contaminantes

\section{Referências}

[1] F.P.J. Barros, Modelos Multidimensionais para Dispersão de Contaminantes em Rios e Canais: Soluções Híbridas por Transformação Integral. Dissertação de Mestrado, COPPE/UFRJ, Rio de Janeiro, RJ. (2004).

[2] H.B. Fischer, J.E. List, R.C.Y. Koh, J. Imberger, N.H. Brooks, Mixing in Inland and Coastal Waters, Academic Press. (1979).

[3] D.M. Moreira, M.T. Vilhena, D. Buske, T. Tirabassi, The State-of-art of the GILTT Method to Simulate Pollutant Dispersion in the Atmosphere. Atmos. Research, vol. 92, pp. 1-17, (2009).

[4] R.I. Nokes, I.R. Wood, Vertical and lateral turbulent dispersion: some experimental results, Journal of Fluid Mechanics, vol. 187, pp. 373-394, (1988). 